\title{
Space Suit Environment Testing of the Orion Atmosphere Revitalization Technology
}

\author{
Amy B. Button ${ }^{1}$ \\ Jacobs Technology/Engineering and Science Contract Group, Houston, Texas, 77058 \\ and \\ Jeffrey J. Sweterlitsch ${ }^{2}$ and Marlon R. Cox ${ }^{3}$ \\ NASA Johnson Space Center, Houston, Texas, 77058
}

\begin{abstract}
An amine-based carbon dioxide $\left(\mathrm{CO}_{2}\right)$ and water vapor sorbent in pressure-swing regenerable beds has been developed by Hamilton Sundstrand and baselined for the Orion Atmosphere Revitalization System (ARS). In three previous years at this conference, reports were presented on extensive Johnson Space Center (JSC) testing of this technology. That testing was performed in a sea-level pressure environment with both simulated and real human metabolic loads, and in both open and closed-loop configurations. The Orion ARS is designed to also support space-suited operations in a depressurized cabin, so the next step in developmental testing at JSC was to test the ARS technology in a typical closed space suit-loop environment with low-pressure oxygen inside the process loop and vacuum outside the loop. This was the first instance of low-pressure, high-oxygen, closed-loop testing of the Orion ARS technology, and it was conducted with simulated human metabolic loads in March 2009. The test investigated pressure drops and flow balancing through two different styles of prototype suit umbilical connectors. General swing-bed performance was tested with both umbilical configurations, as well as with a short jumper line installed in place of the umbilicals. Other interesting results include observations on the thermal effects of swing-bed operation in a vacuum environment and a recommendation of cycle time to maintain acceptable suit atmospheric $\mathrm{CO}_{2}$ and moisture levels.
\end{abstract}

\section{Nomenclature}

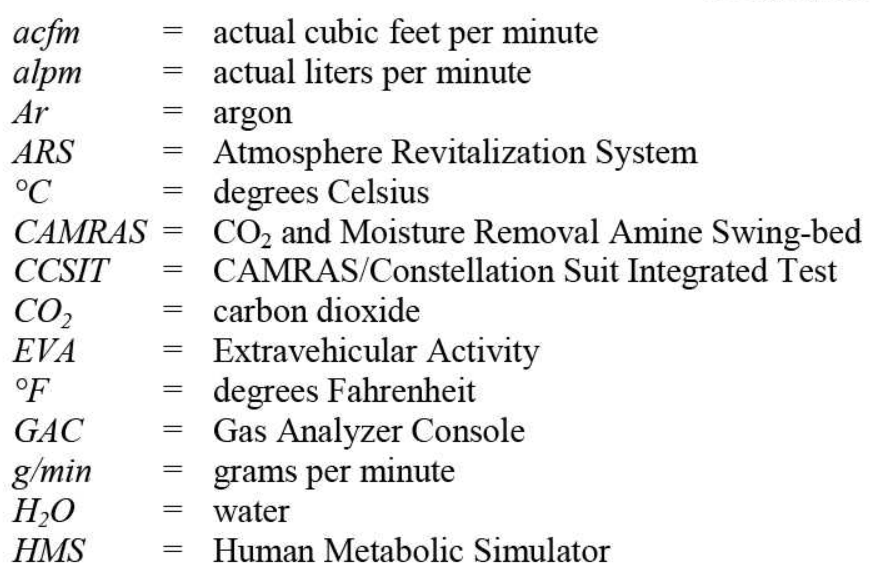

\footnotetext{
${ }^{1}$ Project Engineer, Exploration Life Support Atmosphere Revitalization Systems, 2224 Bay Area Boulevard, Mail Code JE77, AIAA Lifetime Member.

${ }^{2}$ Project Engineer, Exploration Life Support Atmosphere Revitalization Systems, 2101 Nasa Parkway, Mail Code EC3, not an AIAA Member.

${ }^{3}$ Project Engineer, Space Suit and Crew Survival Systems, 2101 Nasa Parkway, Mail Code EC5, not an AIAA Member
} 


$\begin{array}{ll}I V A & =\text { Intravehicular Activity } \\ J S C & =\text { Johnson Space Center } \\ \mathrm{kPa} & =\text { kiloPascals } \\ \mathrm{m} & =\text { meters } \\ \mathrm{min} & =\text { minutes } \\ \mathrm{mmHg} & =\text { millimeters of mercury } \\ \mathrm{N}_{2} & =\text { nitrogen } \\ \mathrm{O}_{2} & =\text { oxygen } \\ \mathrm{Pa} & =\text { Pascals } \\ \mathrm{pp} & =\text { partial pressure (of the named gas) } \\ p s i & =\text { pounds per square inch } \\ p s i d & =\text { pounds per square inch, differential } \\ \text { sccm } & =\text { standard cubic centimeters per minute } \\ \text { scfm } & =\text { standard cubic feet per minute } \\ \text { slpm } & =\text { standard liters per minute }\end{array}$

\section{Introduction}

The CAMRAS/Constellation Suit Integrated Test (CCSIT) series has been established at JSC to evaluate the performance of and provide risk reduction for the baseline Orion ARS technology, which is known at JSC as the $\mathrm{CO}_{2}$ And Moisture Removal Amine Swing-bed (CAMRAS). The CCSIT series examines flight-like scenarios that are more complex than the concurrent CAMRAS performance test series and that are integrated with other vehicle development objectives. CCSIT Phase 2, the topic of this paper, had a primary objective of evaluating the atmospheric metabolic constituent removal capabilities of the CAMRAS unit when operated with low pressure process gas consisting principally of oxygen, in a small volume circulation loop, and without air around the unit to provide convective heat transfer. It is important to note that the CAMRAS technology was originally designed solely for cabin operation. Water vapor and $\mathrm{CO}_{2}$ were injected into the loop to simulate space-suited human metabolic processes. A secondary objective was to evaluate the pressure drop and flow characteristics through prototype umbilicals of two different lengths and with two different styles of connectors. This was the first test of a CAMRAS unit in a reduced pressure, elevated oxygen "suit loop" environment. All prior tests of the full-scale units were conducted at ambient pressure with air.

\section{Test Rig}

\section{A. CAMRAS Test Article}

The CAMRAS technology uses a pair of interleaved multilayer beds filled with sorbent beads. In each CAMRAS unit, a spool-type valve directs airflow from the cabin, through the adsorbing bed, and back to the cabin while isolating the desorbing bed to a direct line to space vacuum. The valve periodically switches position, swapping the bed functions and equalizing pressure between the beds as it travels to help minimize ullage air loss. Each adsorption or desorption period is called a half-cycle. Figure 1 shows a simple schematic of the CAMRAS operation. The left side of the figure shows the spool valve shuttle positioned for bed $\mathrm{A}$ adsorption and bed $\mathrm{B}$ desorption; the right side shows the shuttle in the opposite position and the bed functions swapped. Vacuum pulls on both ends of the desorbing bed.

Highly porous plastic beads coated with an immobilized liquid amine fill

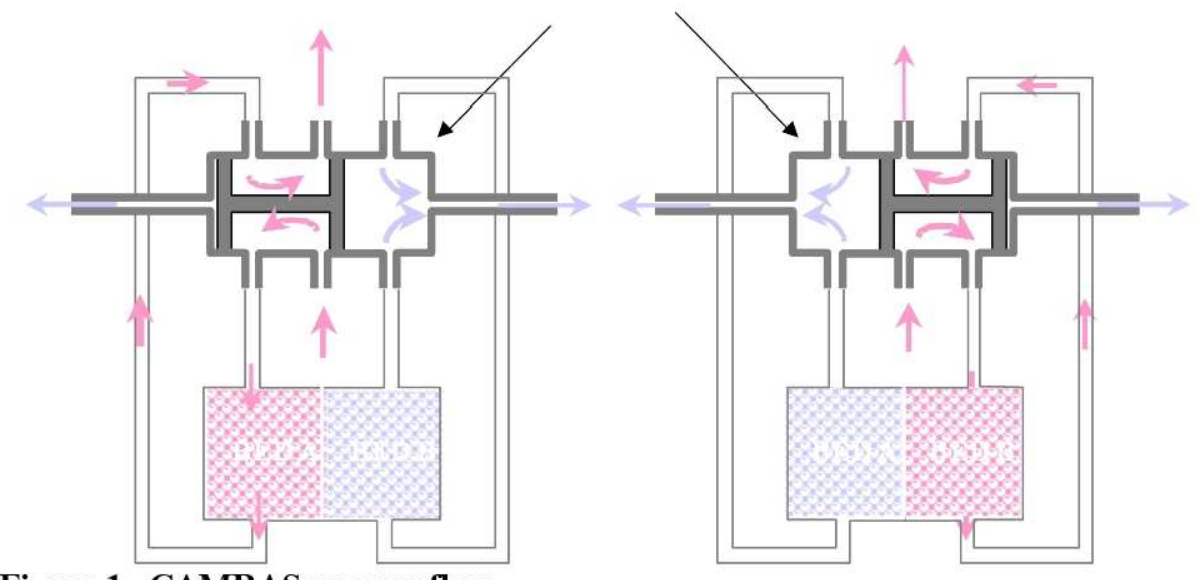

Figure 1. CAMRAS process flow. 
aluminum foam blocks inside each CAMRAS unit and are retained in the foam with aluminum screens. The sorbent, known as SA9T, adsorbs both carbon dioxide and water vapor. The adsorption reaction is exothermic and the desorption reaction is endothermic; the use of aluminum foam and interleaving of bed layers for heat transfer helps conserve the overall system thermal energy so that no direct heating or cooling of the device is required.

In the projected Orion application of this technology, three separate CAMRAS assemblies will be installed in the vehicle. Two would operate in parallel during nominal open-loop cabin operations and closed-loop suited operations with a crew of four people, and the third would be reserved as a spare or for excess capacity. The CAMRAS units are sized such that, in an emergency, a single unit could maintain the cabin $\mathrm{CO}_{2}$ at safe levels indefinitely.

\section{B. Process Loop}

In Phase 2 of CCSIT, one dual-end desorb CAMRAS unit was installed in a chamber as part of a closed process loop to simulate suit-loop operations. The loop was designed to reflect the proposed Orion ARS process loop design as of August 2007. Unlike in previous test series, the chamber atmospheric volume was not relevant because it was not part of the process loop; the chamber volume was evacuated to vacuum to simulate a depressurized Orion cabin. This allowed study of the thermal effects of CAMRAS operation in a vacuum, and the CAMRAS desorbed directly to the chamber volume to simplify the test rig.

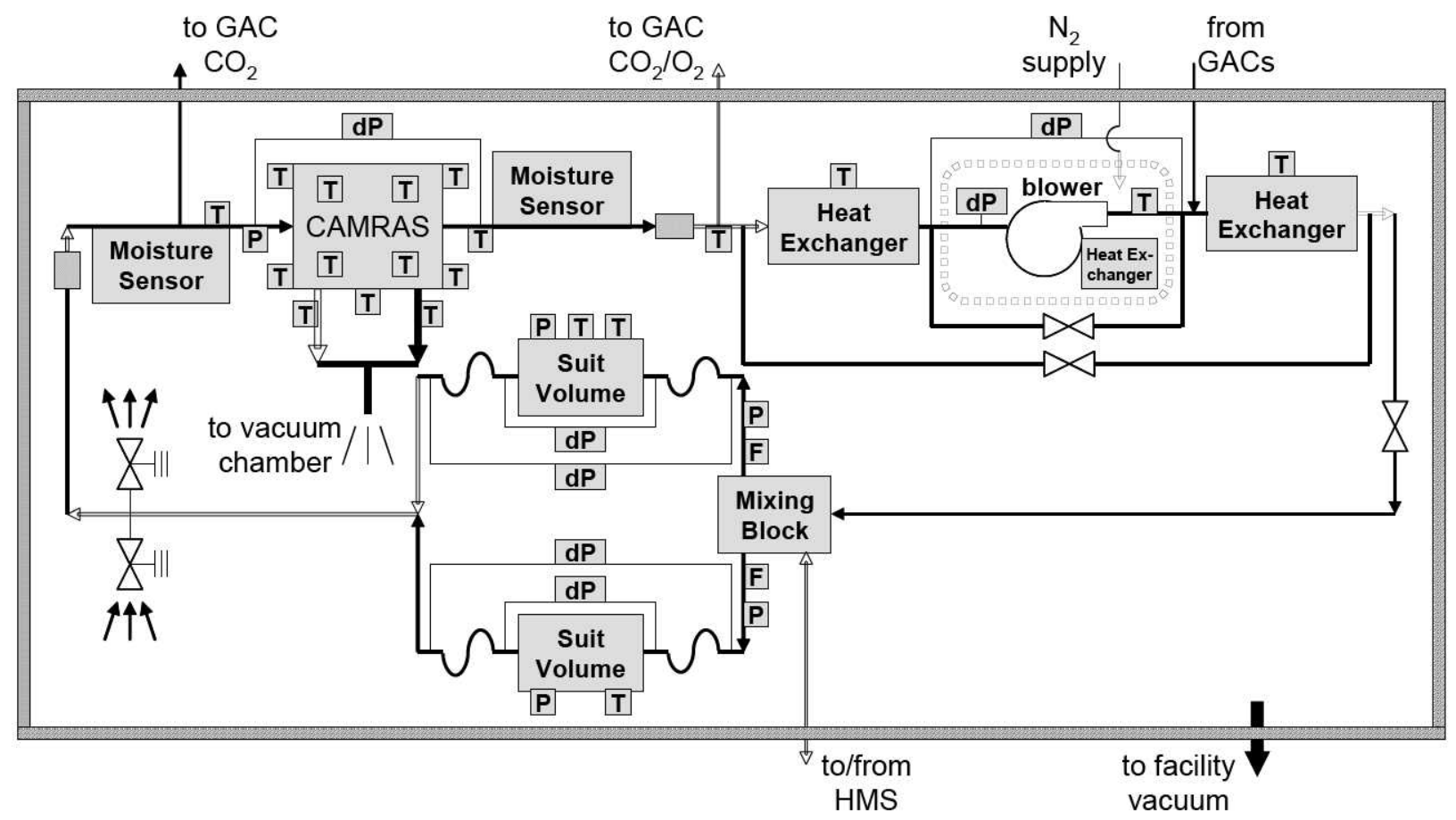

Figure 2. CCSIT Phase 2 test rig schematic.

Figure 2 shows a simple flow schematic of the test rig. Figure 3 on the next page shows a computer model of the test rig inside the chamber. A Human Metabolic Simulator (HMS) simulated human production of $\mathrm{CO}_{2}$ and exhaled water $\left(\mathrm{H}_{2} \mathrm{O}\right)$ vapor, added oxygen $\left(\mathrm{O}_{2}\right)$ to the process loop, and was used to control total pressure of the process gas. A small mixing volume specially designed for this test interfaced with the HMS in the location where a space suit is connected during conventional tests in the chamber. The mixing volume underwent computational fluid dynamics analysis to ensure good mixing of injected HMS gases with the process gas. Flow out of the mixing volume split into two parallel streams to a small pressure vessel, each sized to simulate the free volume in a single space suit. Depending on the test case, one of the suit simulation volumes was connected to the process loop by a short Intravehicular Activity (IVA) umbilical and the other by a long Extravehicular (EVA) umbilical, or both volumes were connected with identical very short paired lengths of standard flexhose. The IVA and EVA umbilicals were prototypes of the Orion design, and each umbilical was designed to carry process gas in both directions through separate internal hoses. These umbilicals are described in more detail in the following section. Process gas returned from the suit volume simulators through the flexhoses or umbilicals and was recombined into a single line routed to the CAMRAS inlet. A single-speed blower pulled the process gas through the CAMRAS, and a bypass system 
balanced with two motorized valves controlled the process flow rate. Heat exchangers cooled the process gas upstream and downstream of the blower (another cooled the blower motor itself), and the process gas exiting the blower flowed back to the HMS mixing volume. The process loop was outfitted with several instruments to analyze the CAMRAS, umbilical, and test rig performance.

The process loop blower was enclosed in a small pressure vessel, called a purge box, in order to reject some blower heat via a low-pressure gas jacket that constantly bled off into the chamber. After testing started, it was strongly suspected that inert gas from the purge box, which was either nitrogen $\left(\mathrm{N}_{2}\right)$ or argon $(\mathrm{Ar})^{*}$, was being continually exchanged with gas in the process loop, thereby preventing the loop from achieving or maintaining the desired near- $100 \% \mathrm{O}_{2}$ concentration. The low pressure in the loop prevented conclusive offline gas sample analysis with the available equipment, but the $\mathrm{O}_{2}$ concentration data was considered reliable due to corroborating sensors. Other $\mathrm{O}_{2}$ replacement mechanism concepts were largely discredited. The unexpected and constantly-changing mix of process gas meant that the readings of some of the loop instruments, most notably the thermal mass flow meters, were inaccurate during the test. The test proceeded using the real-time readings calibrated for $100 \% \mathrm{O}_{2}$. Afterward, the instruments were recalibrated for pure species of each of the process gas constituents, and the test data was adjusted by calculation based on the instantaneous readings of the loop's $\mathrm{CO}_{2}, \mathrm{H}_{2} \mathrm{O}$, and $\mathrm{O}_{2}$ partial pressure mixture, where the remainder was assumed to be the purge box gas. See Ref. 1 for more information on this issue and the calculated data adjustments.

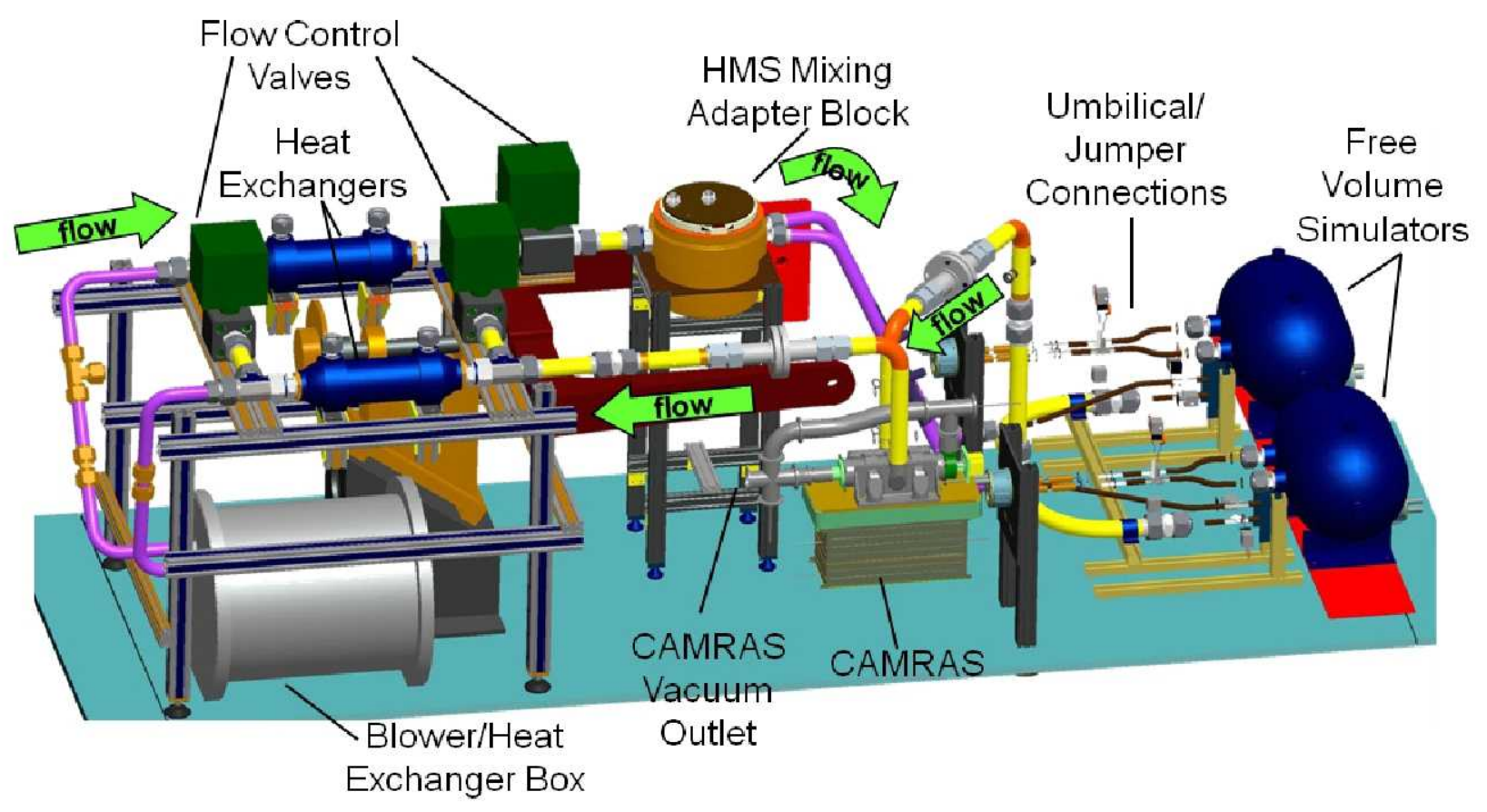

Figure 3. CCSIT Phase 2 three-dimensional test rig model.

\section{Umbilical Test Articles}

The umbilicals used in this test series were prototypes for space suit umbilicals to be used with the Constellation Program vehicles. The umbilicals can plug into the vehicle ARS loop, allowing the CAMRAS hardware and the vehicle to also provide life support functions for suited crew members. Data and communication, cooling water, and breathing gas all flow through the umbilicals, and the umbilicals also serve as tethers for EVA operations. The umbilicals are designed with two different lengths: $3.5 \mathrm{~m}$ ( 11.5 feet) for IVA operations and $8.5 \mathrm{~m}$ ( 28 feet) for EVA operations. In the CCSIT Phase 2 series, two umbilical connector designs, a T-handle cartridge valve and a circular poppet valve, were evaluated for gas pressure drop and flow balancing effects in a realistic flight environment; power, data, and cooling water umbilical functions were not evaluated as part of this test series. These two

\footnotetext{
${ }^{*} \mathrm{~N}_{2}$ was specified as the purge box gas. Ar was tested in an effort to reduce the gas exchange, because it is a larger molecule. Ar did reduce the exchange, so it was used on most subsequent test days, but the umbilical principal investigators specifically requested $\mathrm{N}_{2}$ as the purge gas on umbilical test case days.
} 
umbilical connector designs are pictured in Fig. 4. For each umbilical test case, one of each size umbilical was installed in the test rig, both sizes with the same connector type.

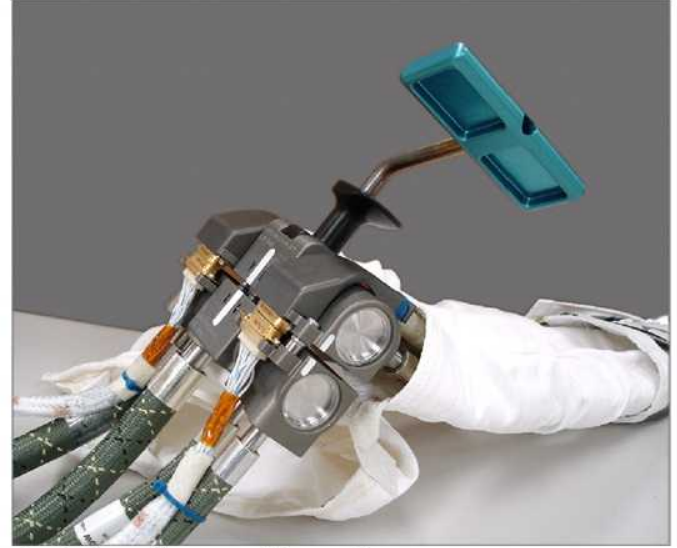

a) T-handle cartridge valve connector.

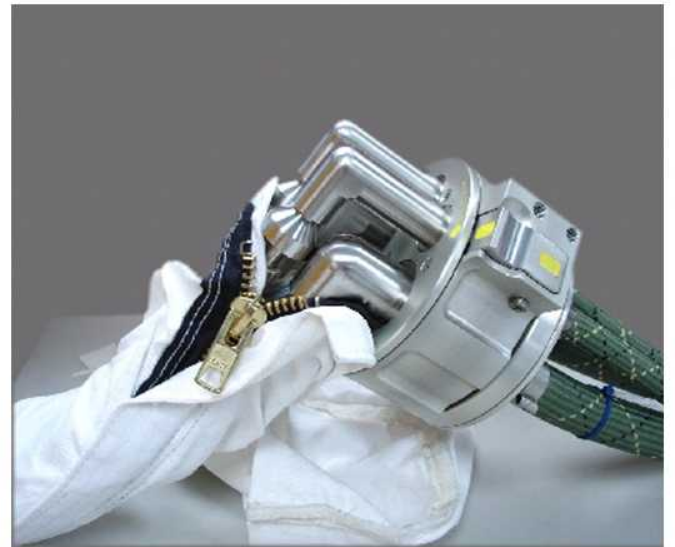

b) Circular poppet valve connector.

Figure 4. Prototype umbilical connectors.

\section{Test Cases}

Fifteen CAMRAS test cases were performed on nine separate test days. An additional two test cases explicitly covered umbilical test objectives, setting different flow rates and recording the pressure drops due to the two different umbilical lengths and connector types. Three principal variables were tested in the CAMRAS portion of the CCSIT Phase 2 series, and these variables are further discussed below:

1) metabolic injection rate and process gas temperature (linked, to prevent condensation)

a) low, representing two passive suited crew members:

i) $497 \mathrm{sccm} \mathrm{CO}$ injection $(0.98 \mathrm{~g} / \mathrm{min})$

ii) $10^{\circ} \mathrm{C}\left(50^{\circ} \mathrm{F}\right) \mathrm{HMS}$ supply dew point

iii) $21.1^{\circ} \mathrm{C}\left(70^{\circ} \mathrm{F}\right)$ temperature (but it usually ended up around $24^{\circ} \mathrm{C}\left(75^{\circ} \mathrm{F}\right)$ )

b) high, representing one active suited crew member and one passive suited crew member:

i) originally $2490 \mathrm{sccm} \mathrm{CO}$ injection $(4.93 \mathrm{~g} / \mathrm{min})$, reduced to $1538 \mathrm{sccm}(3.04 \mathrm{~g} / \mathrm{min})$ midway through the test series (see subsection $\mathrm{B}$ )

ii) $21.1^{\circ} \mathrm{C}\left(70^{\circ} \mathrm{F}\right) \mathrm{HMS}$ supply dew point

iii) $29.4^{\circ} \mathrm{C}\left(85^{\circ} \mathrm{F}\right)$ temperature

2) process loop flow rate

a) low: targeted to $74.5 \mathrm{slpm}(2.63 \mathrm{scfm})$

b) high: targeted to $103.6 \mathrm{slpm}(3.66 \mathrm{scfm})$

3) cycle time
a) 3 minutes
b) 6.5 minutes
c) 15 minutes
d) manual, based on outlet $\mathrm{CO}_{2}$ concentration peaks of $1.60 \%$ (approximately $480 \mathrm{~Pa} \mathrm{ppCO}_{2}$, or 3.6 $\mathrm{mmHg}$ )

Table 1 shows a summary of the CAMRAS test cases. Case $7^{*}$ was not in the original plan; it was a modification of case 7 that was added after it became apparent that test case 7 was not a realistically viable test point. The actual flow rates, metabolic rates, and temperatures in each of these cases, as run, differed slightly due to the variability in the system controls. The actual test case conditions and preliminary test results are summarized later in this paper. 
Table 1. CAMRAS test case summary.

\begin{tabular}{|c|c|c|c|c|c|c|}
\hline Date & $\begin{array}{l}\text { Connector } \\
\text { Hose Type }\end{array}$ & $\begin{array}{l}\text { Purge } \\
\text { Box Gas }\end{array}$ & $\begin{array}{c}\text { Test } \\
\text { Case \# }\end{array}$ & $\begin{array}{l}\text { Metabolic Rate } \\
\text { \& Temperature }\end{array}$ & $\begin{array}{l}\text { Flow } \\
\text { Rate }\end{array}$ & $\begin{array}{c}\text { Cycle } \\
\text { Time (min) }\end{array}$ \\
\hline $3 / 19 / 09$ & flexhoses & $\overline{\mathrm{Ar}}$ & $\overline{1}$ & low & high & 6.5 \\
\hline $3 / 20 / 09$ & flexhoses & $\overline{\mathrm{Ar}}$ & 5 & low & high & 3 \\
\hline $3 / 23 / 09$ & flexhoses & $\mathrm{Ar}$ & 6 & low & high & 15 \\
\hline \multirow[t]{3}{*}{$3 / 24 / 09$} & \multirow{3}{*}{ flexhoses } & \multirow[t]{3}{*}{$\mathrm{Ar}$} & 2 & low & low & 6.5 \\
\hline & & & 4 & high - original & high & 6.5 \\
\hline & & & 8 & high - original & high & 3 \\
\hline \multirow[t]{2}{*}{$3 / 25 / 09$} & \multirow[t]{2}{*}{ flexhoses } & \multirow[t]{2}{*}{$\mathrm{Ar}$} & 7 & high - original & low & 15 \\
\hline & & & $7 *$ & high - original & high & 15 \\
\hline \multirow[t]{2}{*}{$3 / 27 / 09$} & \multirow[t]{2}{*}{ T-handle umbilicals } & \multirow[t]{2}{*}{$\mathrm{N}_{2}$} & 9 & low & high & 6.5 \\
\hline & & & 13 & low & high & 3 \\
\hline \multirow[t]{2}{*}{$4 / 1 / 09$} & \multirow[t]{2}{*}{ T-handle umbilicals } & \multirow[t]{2}{*}{$\overline{\mathrm{Ar}}$} & 12 & high - modified & high & 6.5 \\
\hline & & & 19 & high-modified & high & manual \\
\hline $4 / 2 / 09$ & T-handle umbilicals & $\mathrm{Ar}$ & 15 & high - modified & low & 15 \\
\hline \multirow[t]{2}{*}{$4 / 3 / 09$} & \multirow[t]{2}{*}{ circular umbilicals } & \multirow[t]{2}{*}{$\overline{\mathrm{N}_{2}}$} & 10 & low & low & 6.5 \\
\hline & & & 20 & low & low & manual \\
\hline
\end{tabular}

The umbilical test cases were short and simple compared to the CAMRAS test cases. The primary item of interest was the pressure drop through each umbilical at different process loop flow rates. Two tests were run, one with each type of umbilical connector, with a range of five flow rates into each length of umbilical. IVA umbilical flow was tested from 113 to $170 \mathrm{alpm}(4.0$ to $6.0 \mathrm{acfm})$, in $14 \mathrm{alpm}(0.5 \mathrm{acfm})$ increments, and EVA umbilical flow was tested from 142 to $198 \mathrm{alpm}(5.0$ to $7.0 \mathrm{acfm})$, also in $14 \mathrm{alpm}$ increments. At each point, the corresponding flow rate through the other umbilical was noted, as were the pressure drops at both the test rig ends of the umbilicals and the suit simulator volume ends of the umbilicals.

\section{A. Steady State Operations Variances}

The goal was to run each test case to steady state CAMRAS operation conditions, historically defined as the process loop atmosphere at the CAMRAS inlet maintaining steady small cycles of moisture and $\mathrm{CO}_{2}$ levels during CAMRAS operation. In this definition, the average levels of both constituents should reach highly repeatable values, with nondirectional variation of less than $0.01 \% \mathrm{CO}_{2}$ and $0.5^{\circ} \mathrm{F}$ dew point during a period of at least 6 halfcycles. Ideally, the variations should be smaller. In CCSIT Phase 2, the HMS drove the CAMRAS inlet conditions and maintained them at relatively stable levels at all times, so dynamic repeatability in the CAMRAS outlet conditions was sought instead.

Even though steady state operation was the ultimate goal of each test case, the large number of manuallycontrolled variables in the system and some imprecisely sized equipment combined to ensure that at least one temperature, pressure, gas concentration, or flow rate was not as steady as preferred in most of the CCSIT Phase 2 cases. However, most cases did achieve the minimum required dynamic steady state CAMRAS outlet average $\mathrm{CO}_{2}$ and water vapor conditions. The 15-minute cycle time cases were either aborted due to offscale-high CAMRAS inlet $\mathrm{CO}_{2}$ readings (cases 7 and $7^{*}$ ) or were stopped after 8 hours, which was determined to be the maximum realistic EVA duration (cases 6 and 15). The low metabolic rate manual cycle time case (case 20) may have nominally been an 8-hour cutoff case, but it was run as the last of several cases on the last available test day.

\section{B. Metabolic $\mathrm{CO}_{2}$ and Water Vapor Injection Variances}

The HMS for this test series did not control water on a mass basis; instead, it maintained a target supply line dew point. The dew point selection for these tests assumed that the water was being injected into a dry air stream. For the high metabolic rate, the target dew point required more air flow than the HMS could provide, so the $21.1^{\circ} \mathrm{C}$ value was accepted as a compromise. Unfortunately, this decision making process did not account for the fact that the HMS air stream was recirculated from the same mixing volume where the supply stream mixed with the process loop gas. Because of this configuration, there was some moisture already in the HMS supply gas before more water was added to achieve the target dew point, meaning that the actual mass of water injected was significantly lower than intended and was not directly quantifiable. 
After the first two days of high metabolic rate testing, the appropriateness of the $2490 \mathrm{sccm} \mathrm{CO} \mathrm{CO}_{2}$ injection rate target was called into question. It was determined that it was not realistic for the active crew member to work at peak load for a full eight-hour period, as had been effectively assumed when selecting the original injection rate, and further review of the Constellation Program's Human-Systems Integration Requirements ${ }^{2}$ upheld that conclusion. Consequently, the $\mathrm{CO}_{2}$ injection rate was reduced to $1538 \mathrm{sccm}$ for the remaining test cases to reflect the active crew member's average metabolic rate over an entire EVA.

\section{Loop Flow Rate Variances}

The standard volumetric gas flow rate in the process loop, although nominally set to one of two different flow rates, actually varied somewhat. Achieving the nominal flow rate setpoint was difficult to do with high accuracy due to slop in the flow control valve motor linkage. Furthermore, maintaining the flow rate setpoint with high accuracy was not possible due to constant variations in loop pressure due to CAMRAS valve cycling and manuallycontrolled makeup gas injections to loop and purge box, as well as continual variations in the loop gas composition that affected the accuracy of the flow meter readings relative to their calibration curves.

While the raw flow rate readings were correctable by calculation after the end of the test series, it did mean that a few of the umbilical flow rate test points were inadvertently not examined. Because the process loop flow rate adjustment was manual and delicate, it required some trial and error to obtain flow rate readings close to the desired test points. A wide range of flow rates were transiently examined in the process, however, so moderately robust flow-pressure drop curves were generated, which compensated for some of the lost data. It was also discovered after the T-handle connector test points but before the circular connector test points that the flow meters on the two umbilical lines were cross-connected. Post-test data correction enabled the collected data to be used, but it did mean that a few of the desired test points were missed for the T-handle connector. 


\section{CAMRAS Performance Test Results}

Table 2 summarizes the preliminary evaluations of the average loop conditions during the steady state period (or end period, if steady state was not achieved) of each of the CCSIT Phase 2 cases. Columns shaded black indicate that no test cases were run for that point in the matrix. Cells with the same shading pattern are directly comparable cases. Cases 6, 7, 7*, 15, and 20 did not meet the steady state criteria. Arrows beside removal efficiencies note the direction of movement of the average efficiency for cases that were not steady; case 20 had so few and such long cycles that a movement direction could not be stated with assurance.

Table 2. Average test results matrix.

\begin{tabular}{|c|c|c|c|c|c|c|}
\hline \multirow{3}{*}{$\begin{array}{l}\text { Flow Rate } \\
\text { Cycle Time } \\
\text { Low Metabolic Rate Case }\end{array}$} & \multicolumn{2}{|c|}{ Low Flow Rate } & \multicolumn{4}{|c|}{ High Flow Rate } \\
\hline & $6.5 \mathrm{~min}$ & \multirow{2}{*}{$\begin{array}{c}\mathbf{1 5}(+) \mathbf{m i n} \\
\mathbf{2 0} \\
(\sim 69.2 \mathrm{~min}) \\
\end{array}$} & \multirow{2}{*}{$\frac{15(+) \min }{6}$} & $6.5 \mathrm{~min}$ & \multicolumn{2}{|c|}{$3 \mathrm{~min}$} \\
\hline & 10 & & & 1819 & 5 & 13 \\
\hline Inlet Pressure $(\mathrm{kPa})$ & 29,02 & 28.47 & 28.36 & 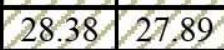 & 28.72 & 27.81 \\
\hline Inlet Temperature $\left({ }^{\circ} \mathrm{C}\right)$ & $23.90 \quad 24.22$ & 25.65 & 25.25 & $2 3 8 9 \longdiv { 2 4 . 7 9 }$ & 23.47 & 25.05 \\
\hline Outlet $\mathrm{O}_{2}$ Concentration (\%) & 741 & 48.5 & 66.5 & $701 \quad 52.5$ & 70.9 & 53.4 \\
\hline Process Flow Rate (alpm) & 201 & 201 & 283 & \begin{tabular}{l|l}
281 & 261 \\
\end{tabular} & 271 & 260 \\
\hline Inlet $\mathrm{ppCO}_{2}(\mathrm{~Pa})$ & 202 & 297 & 133 & $1 3 2 \longdiv { 1 2 9 }$ & 140 & 129 \\
\hline Outlet $\mathrm{ppCO}_{2}(\mathrm{~Pa})$ & $\theta$ & 100 & 0 & $60 \angle 0$ & 0 & 0 \\
\hline $\mathrm{CO}_{2}$ Removal Efficiency (\%) & 100 & 77.5 & 100 & $1 0 0 \longdiv { 1 0 0 }$ & 100 & 100 \\
\hline Inlet Dew Point $\left({ }^{\circ} \mathrm{C}\right)$ & 0.11 & 4.01 & -2.74 & $\begin{array}{ll}-2,42 & -2,48 \\
\end{array}$ & -2.67 & -2.35 \\
\hline Outlet Dew Point $\left({ }^{\circ} \mathrm{C}\right)$ & $-29.20 \quad-23.86$ & -5.60 & -22.58 & $-29.31-29.26$ & -23.90 & -27.55 \\
\hline $\mathrm{H}_{2} \mathrm{O}$ Removal Efficiency (\%) & $9 3 3 \longdiv { 8 8 . 7 }$ & 45.1 & $80.4 \downarrow$ & $\begin{array}{l}91.8 \\
917\end{array}$ & 85.5 & 90.3 \\
\hline Cycling Vacuum Pressure $(\mathrm{Pa})$ & 7 & 5 & 7 & 6712 & 8 & 7 \\
\hline $\begin{array}{l}\text { Modified High Metabolic Rate } \\
\text { Case }\end{array}$ & & 15 & $\begin{array}{c}19 \\
(16.9 \mathrm{~min})\end{array}$ & 12 & & \\
\hline Inlet Pressure $(\mathrm{kPa})$ & & 28.12 & 27.26 & 27.76 & & \\
\hline Inlet Temperature $\left({ }^{\circ} \mathrm{C}\right)$ & & 28.90 & 28.87 & 29.00 & & \\
\hline Outlet $\mathrm{O}_{2}$ Concentration (\%) & & 52.5 & 62.3 & 63.7 & & \\
\hline Process Flow Rate (alpm) & & 196 & 263 & 266 & & \\
\hline Inlet $\mathrm{ppCO}_{2}(\mathrm{~Pa})$ & & 747 & 550 & 505 & & \\
\hline Outlet $\mathrm{ppCO}_{2}(\mathrm{~Pa})$ & & 28 & 83 & 15 & & \\
\hline $\mathrm{CO}_{2}$ Removal Efficiency (\%) & & $96.4 \downarrow$ & 87.1 & 97.0 & & \\
\hline Inlet Dew Point $\left({ }^{\circ} \mathrm{C}\right)$ & & 16.05 & 14.18 & 13.73 & & \\
\hline Outlet Dew Point $\left({ }^{\circ} \mathrm{C}\right)$ & & -16.71 & -9.92 & -13.68 & & \\
\hline $\mathrm{H}_{2} \mathrm{O}$ Removal Efficiency (\%) & & $91.8 \downarrow$ & 81.5 & 88.1 & & \\
\hline Cycling Vacuum Pressure $(\mathrm{Pa})$ & & 8 & 8 & 10 & & \\
\hline $\begin{array}{l}\text { Original High Metabolic Rate } \\
\text { Case }\end{array}$ & & 7 & $7 *$ & & 8 & \\
\hline Inlet Pressure $(\mathrm{kPa})$ & & 29.09 & 28.16 & 27.90 & 27.73 & \\
\hline Inlet Temperature $\left({ }^{\circ} \mathrm{C}\right)$ & & 29.26 & 29.76 & 28.82 & 28.66 & \\
\hline Outlet $\mathrm{O}_{2}$ Concentration (\%) & & 72.3 & 69.7 & 73.8 & 74.9 & \\
\hline Process Flow Rate (alpm) & & 197 & 273 & 264 & 261 & \\
\hline Inlet $\mathrm{ppCO}_{2}(\mathrm{~Pa})$ & & $1401^{\wedge}$ & $1112^{\wedge}$ & 795 & 787 & \\
\hline Outlet $\mathrm{ppCO}_{2}(\mathrm{~Pa})$ & & 248 & 323 & 45 & 29 & \\
\hline $\mathrm{CO}_{2}$ Removal Efficiency (\%) & & $91.5 \uparrow$ & $85.4 \downarrow$ & 94.4 & 96.3 & \\
\hline Inlet Dew Point $\left({ }^{\circ} \mathrm{C}\right)$ & & 15.66 & 13.61 & 13.75 & 13.70 & \\
\hline Outlet Dew Point $\left({ }^{\circ} \mathrm{C}\right)$ & & -16.27 & -12.06 & -14.73 & -14.38 & \\
\hline $\mathrm{H}_{2} \mathrm{O}$ Removal Efficiency (\%) & & $90.8 \uparrow$ & $83.8 \downarrow$ & 89.1 & 88.8 & \\
\hline Cycling Vacuum Pressure $(\mathrm{Pa})$ & & 8 & 8 & 10 & 12 & \\
\hline
\end{tabular}

${ }^{\wedge}$ These values use the HMS Return reading because the CAMRAS inlet analvzer pegged at $5 \%$ concentration. 


\section{A. CAMRAS Performance}

The most notable difference in this test as compared to virtually all the earlier tests of the CAMRAS units is that, in this series, the $\mathrm{CO}_{2}$ adsorption efficiency was higher than that of water vapor. The CCSIT Phase 1 respirator test cases had the most analogous test conditions to this test series, at least in terms of loop volume and flow rate, and they showed roughly equal scrubbing efficiencies with the same CAMRAS unit. (However, those cases did not target steady state conditions, so the efficiencies were not formally reported.) The CCSIT Phase 1 respirator test results also show that the $\mathrm{CO}_{2}$ scrubbing efficiency exceeded that of $\mathrm{H}_{2} \mathrm{O}$ at the lowest process flow rates, which were comparable to the actual flow rates used in these CCSIT Phase 2 tests.

The average inlet and outlet $\mathrm{CO}_{2}$ and dew point readings presented in Table 2 must be clarified: the range of readings during each half-cycle was either wide or narrow; longer spool valve cycle times typically induce larger swings, particularly on the outlet side of the CAMRAS, which is the side supplying scrubbed air to the crew. In case 7*, for example, although the average outlet $\mathrm{ppCO}_{2}$ was only $323 \mathrm{~Pa}(2.42 \mathrm{mmHg})$, at the end of each halfcycle the reading peaked at over $1300 \mathrm{~Pa}(9.75 \mathrm{mmHg})$, which is not considered acceptable breathing air. For Orion cabin operations, the atmosphere moisture range is targeted between $25 \%$ relative humidity and about $7{ }^{\circ} \mathrm{C}\left(45^{\circ} \mathrm{F}\right)$ dew point. The minimum relative humidity value ensures a comfortable crew; the maximum dew point prevents condensation on the uninsulated vehicle coolant lines. All of these CCSIT Phase 2 cases suffered from CAMRAS outlet (crew breathing gas) dew points far too low for extended comfort, although some of the discrepancy can be attributed to the previously-discussed undersupply of water by the HMS. Low process flow rates and long halfcycle times promote high average outlet dew points; cases 19 and 20 demonstrated that controlling the spool valve cycle time for a peak outlet $\mathrm{CO}_{2}$ reading kept the crew gas supply's $\mathrm{CO}_{2}$ content at safe levels and significantly raised its average dew point.

\section{B. CAMRAS Environment Temperature Effects}

Tests in the CAMRAS Phase 1 series had demonstrated that the ambient/process gas temperature has a minor effect on CAMRAS performance. Removal efficiency of both $\mathrm{CO}_{2}$ and $\mathrm{H}_{2} \mathrm{O}$ decrease as temperature rises above or falls below approximately $20^{\circ} \mathrm{C}\left(68^{\circ} \mathrm{F}\right)$. Water vapor efficiency is more significantly affected by temperature increases than is $\mathrm{CO}_{2}$, so some of the performance variation seen between low and high metabolic rate cases in CCSIT Phase 2 can be attributed to temperature effects.

Half-cycle temperature swings inside the CAMRAS beds during the CCSIT Phase 2 tests were comparable to those during sea level pressure cabin configuration tests at roughly similar load conditions. This suggests that the loss of ambient convective cooling due to the vacuum chamber environment had a minimal effect on the CAMRAS unit's temperature and performance. It is important to remember, however, that water load has a strong effect on CAMRAS bed temperatures because water reactions generate most of the sorbent's temperature swings.

\section{Umbilical Performance Test Results}

Umbilical prototypes of different designs were tested to compare each to the pressure drop requirements established by the vehicle programs. A pressure drop of $0.772 \mathrm{kPa}(0.112 \mathrm{psid})$ per umbilical is allowed for a target flow rate of $127 \mathrm{alpm}$ (4.5 acfm) in IVA umbilicals, and a pressure drop of $2.63 \mathrm{kPa}(0.381 \mathrm{psid})$ per umbilical is allowed for a target flow rate of $170 \mathrm{alpm}(6.0 \mathrm{acfm})$ in EVA umbilicals. Although some of the CCSIT Phase 2 data had to be extrapolated to address the desired flow rate test points, it was found that the collected T-handle connector data trended well with a MacroFlow analysis model. There was no existing analysis model for the circular connector.

The IVA T-handle connector pressure drop, at $0.97 \mathrm{kPa}(0.14 \mathrm{psid})$, was over the umbilical allocation but within the $20 \%$ EVA system margin. The IVA circular connector induced a larger pressure drop, more than $40 \%$ over the allocation at $1.1 \mathrm{kPa}(0.16 \mathrm{psid})$. The extrapolated EVA T-handle pressure drop, $2.3 \mathrm{kPa}(0.33 \mathrm{psid})$, was within the allocation and close to the $2.44 \mathrm{kPa}(0.354 \mathrm{psid})$ MacroFlow model prediction. The extrapolated EVA circular connector data suggested a much larger pressure drop of $4.0 \mathrm{kPa}(0.58 \mathrm{psid}), 50 \%$ over the allocation. These test results are summarized in Fig. 5. 


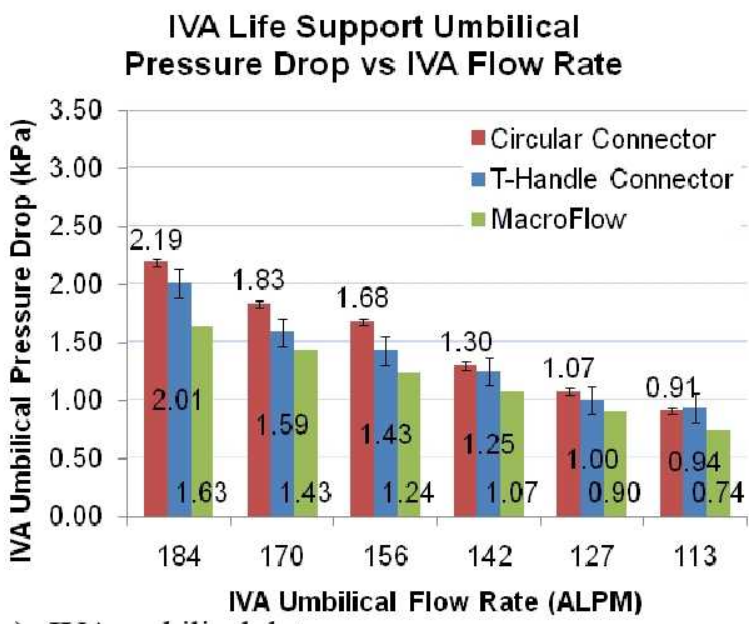

a) IVA umbilical data.
EVA Life Support Umbilical Pressure Drop Vs EVA Flow Rate

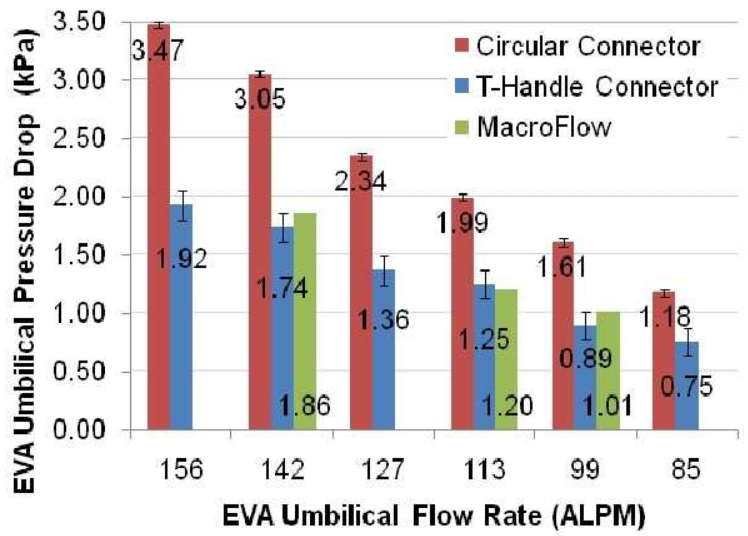

b) EVA umbilical data.

Figure 5. CCSIT Phase 2 umbilical pressure drops versus flow rates.

The circular connector showed higher IVA flow rates than the T-handle connector at the same EVA flow rates. The relative flow rates through the two umbilical lengths are important because both types of umbilicals will be in simultaneous parallel-plumbed use in the system during an EVA. When the ARS loop flow rate is set to provide the desired 170 alpm through the EVA umbilical, the resulting IVA umbilical flow rate may then be higher than the desired $127 \mathrm{alpm}$. The average IVA umbilical to EVA umbilical flow rate ratios were 1.21 for T-handle connectors, 1.27 for the T-handle analysis model projections, and 1.47 for the circular connectors. The full ranges of paired umbilical flow rates for the T-handle, T-handle analysis model, and circular connectors are shown in Fig. 6. This test data will help determine the necessary level of flow attenuation required in the IVA umbilical design to balance the flow rates between the two umbilical types.

\section{Constellation Life Support Umbilical IVA vs EVA Flow Rates}

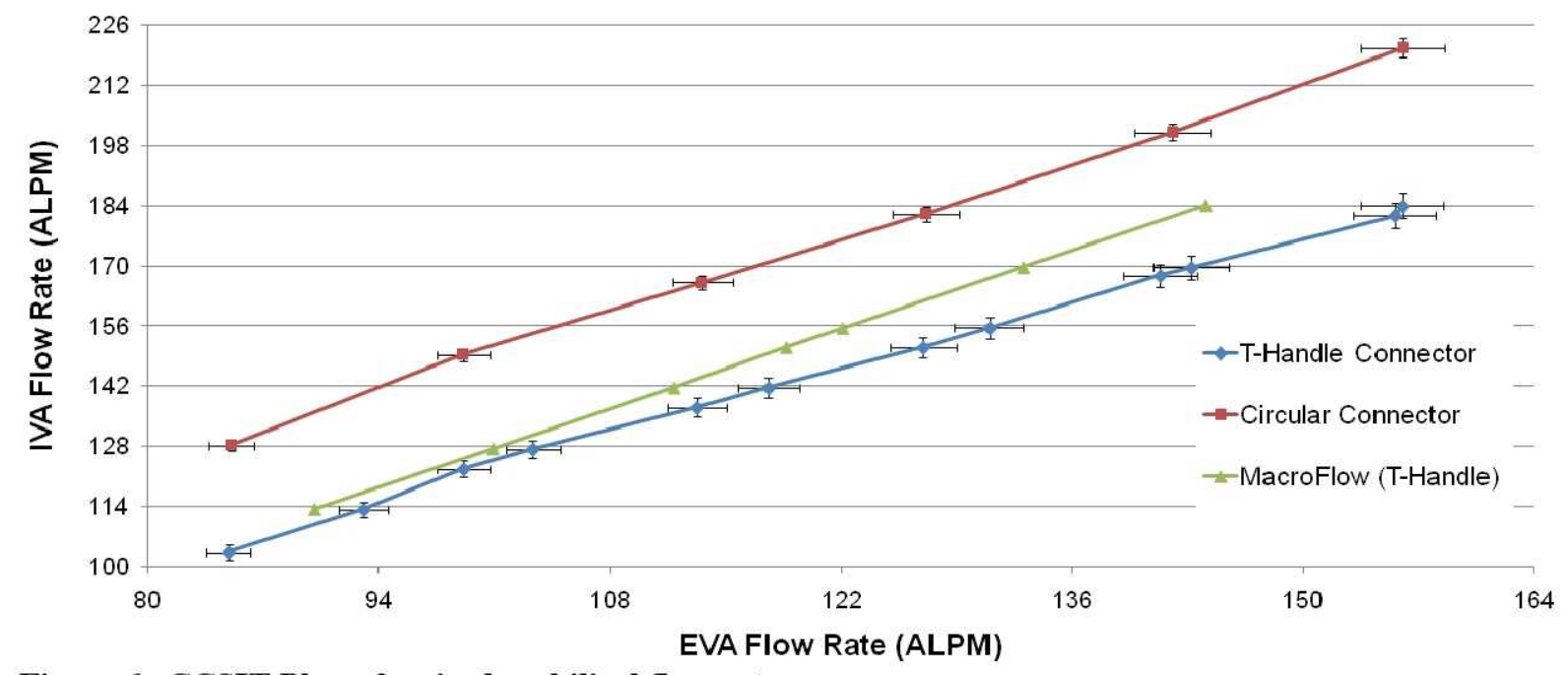

Figure 6. CCSIT Phase 2 paired umbilical flow rates.

\section{Summary, Conclusions, and Future Work}

CCSIT Phase 2 was an overall success. Although there were numerous problems both large and small in the collection and analysis of the data, and certain objectives had to be compromised, the majority of the test objectives were met. Many lessons were learned about how to design a better test rig for similar future endeavors. Full-scale CAMRAS technology has now been safely and successfully tested:

- with a space suit-pressure process gas environment.

- with a predominantly oxygen process gas environment. 
- with a process loop volume similar to that of the Orion vehicle suit loop.

- in a vacuum environment, without convective ambient or other dedicated cooling of the unit exterior.

The performance of the CAMRAS unit in this environment seems, at initial review, to be very comparable to its performance in the ambient-pressure cabin and emergency breathing mask loops previously tested. Due to the small volume of the suit loop, the crew is likely to be most comfortable with long CAMRAS valve cycle times, on the order of one hour for low levels of activity or one-quarter hour for high levels of activity. These cycle times may yield low suit humidity levels, but they will be the highest possible while maintaining reasonable $\mathrm{CO}_{2}$ levels. Operation in a vacuum did not significantly affect the CAMRAS unit's thermal operations.

Umbilical data collected in CCSIT Phase 2 contributed to the elimination of the circular connector design. It is desirable for both pressure drop and flow rate variance to be minimized so that the umbilical has minimal impact on ARS loop operations. The circular connector with poppet valves yielded higher pressure drop and higher flow rate variance between the IVA and EVA umbilical lengths than the T-handle design with cartridge valves. Various design changes to the T-Handle design's breathing gas loop are currently being traded to address the IVA/EVA flow variance, and the best option will be incorporated into the next umbilical design cycle.

CCSIT Phase 3, targeted for fiscal year 2011, will use humans to provide metabolic loads for the CAMRAS in both reduced pressure cabin and space suit environments. Next-generation umbilicals will be used to connect two test subjects in Space Shuttle/Space Station-type space suits without their Portable Life Support Systems to the test ARS loop, which will contain a later-generation CAMRAS unit for $\mathrm{CO}_{2}$ and water vapor removal. CCSIT Phase 3 will serve as a proof of concept for the complete range of CAMRAS functional environments and for operability of the Life Support Umbilical, and will include testing of the umbilical's cooling water, data, and communication functions.

\section{Acknowledgments}

The authors would like to acknowledge Tim Nalette and Bill Papale of Hamilton Sundstrand Space Systems International for providing the CAMRAS test article and preliminary test data, technical support during the JSC tests, and subsequent analysis insights. NASA's Exploration Life Support (ELS) Program, Constellation Program, and Crew and Thermal Systems Division helped fund the CCSIT Phase 2 testing program. JSC Test Director Cristina Anchondo and her backup team made sure that the tests were properly documented and were conducted smoothly and safely. Members of the JSC Exploration Life Support Air Revitalization team (Mary Walsh, Jeffrey Sweterlitsch, Amy (Lin) Button, Melissa Campbell, Su Curley, Javier Jimenez), the Space Suit and Crew Survival Systems Vehicle Interface Element team (Marlon Cox, Eric Falconi, and Nicole Jordan), and technical consultants John Graf and Ram Allada were instrumental in helping design the test points. Craig Bernard and John Cornwell led the test development team; Jeff Sweterlitsch was the principal scientist; Amy Button was the lead CAMRAS test conductor, data analyst, and report writer; and Marlon Cox was the lead umbilical test conductor, data analyst, and report writer. JSC Test Facility Engineers Eric Gutierrez, Jason Pond, and Jose Cervantes designed and directed the test rig development by a large team of technicians, and Javier Jimenez managed many of the other buildup logistics. W. Danny Harwell created detailed three-dimensional chamber and test rig models that enabled all of the test equipment and its associated plumbing to fit inside the chamber without disturbing flight-critical chamber equipment. Jon Golden of Hamilton Sundstrand led the design of the process loop blower and flow control system. Sarah Smith at White Sands Test Facility provided oxygen safety analyses of the test rig components. Keelan Hamilton performed gas composition sampling. This test and this paper would not have been possible without their help.

\section{References}

\footnotetext{
${ }^{1}$ Lin, A., "CCSIT Phase 2 Quick-Look Test Report: CAMRAS Performance," JSC 47197, Johnson Space Center, Houston,

${ }^{2}$ National Aeronautics and Space Administration, "Constellation Program Human-Systems Integration Requirements, Rev. B, CxP 70024, 2008.
} TX, 2009. 